\title{
Decision-Making Optimization of Risk-Seeking Retailer Managed Inventory Model in a Water Supply Chain
}

\author{
Wenfang Yu, Guisheng Hou, and Baogui Xin \\ College of Economics and Management, Shandong University of Science and Technology, Qingdao 266590, China \\ Correspondence should be addressed to Baogui Xin; xin@sdust.edu.cn
}

Received 5 March 2021; Revised 29 March 2021; Accepted 15 April 2021; Published 27 April 2021

Academic Editor: Wei Zhang

Copyright (C) 2021 Wenfang Yu et al. This is an open access article distributed under the Creative Commons Attribution License, which permits unrestricted use, distribution, and reproduction in any medium, provided the original work is properly cited.

\begin{abstract}
Water retailer managed inventory is a classical and inevitable inventory management mode in present economic society. Stochastic models can more clearly explain demand uncertainty and are closely related to water supply chains. Risk preferences are widely valued in behavioral operation management. Related to the risk preferences in inventory management, the research on risk aversion is dominant, while risk-seeking is insufficient. Based on the model assumptions, the risk-seeking retailer's optimal decision-making inventory model with stochastic demand in a water supply chain is studied. The risk-seeking retailer's optimal inventory quantity, optimal inventory cost, supplier profit, retailer profit, and the profit of the entire water supply chain are derived. The validity of the equations is proved. The sensitivity analysis of the risk-seeking retailer's optimal inventory decisionmaking is carried out. The risk level effects on the five dimensions, the retail price, wholesale price, unit shortage cost, unit inventory cost, and unit residual value, are displayed through numerical simulation. The optimal inventory quantity and optimal inventory cost of the risk-seeking retailer are obtained.
\end{abstract}

\section{Introduction}

1.1. Background. With the global population growth and economic development, water resources are becoming increasingly scarce. Water is a crucial business resource, but subsistent evidence suggests that the management of water resources is often poorly operated [1]. According to the United Nations World Water Development Report 2019, 45 percent of global GDP will be in the face of risk by 2050, if the natural environment and the unbearable pressures on worldwide water resources continue to degenerate at current rates. 40 percent of worldwide grain production is in the same situation. Moreover, the aggregate risk of displacement due to disasters has increased twofold since the 1970s. The exhaustion of water and other natural resources is progressively seen as the driving force behind the displacement of internal and international migration. Rogers et al. [2] considered water as an economic commodity and used prices to motivate efficiency, equity, and sustainability. In China, a series of regulations were issued to regulate water resources management. For example, "Urban Water Supply
Regulations" (China State Council 2018) regulate the use of water for urban life, production, and other constructions. "Industrial Water Usage Quota for 18 Industries including Iron and Steel Industry" (Ministry of Water Resources China 2019) stipulates bound boundaries for water use in high-water-consumption industries. It is predicted that the "Industrial Water Usage Quota for 18 Industries including Iron and Steel Industry" will save 1 billion cubic meters of water annually after it is strictly implemented. Because water has commodity properties, research on water resources from the perspective of supply chain has been paid more and more attention.

In the traditional supply chain, retailers are at the end of the supply chain and directly face customers. On the one hand, the retailer keeps inventory and decides the inventory level to deal with demand uncertainty. On the other hand, the retailers also have to bear the shortage cost due to stockout. It is little motivated for upstream suppliers to reserve buffer stock to meet demand of end-users [3]. This classical inventory management mode is the retailer managed inventory (RMI) that is also known as customer 
managed inventory (CMI). The retailer retains the ownership of the inventory and accordingly bears the inventory cost, management cost, and some risks and responsibilities [4]. The upstream enterprise and the retailer in the supply chain are two completely independent individuals who own and manage inventory independently. The two parties transact business without cooperative management of inventory. Meanwhile, both parties bear various costs and risks caused by uncertain market demand, respectively, as shown in Figure 1.

Uncertainty is an essential feature of market. As the internal and external environments change rapidly, the uncertainty increases significantly. Several international organizations made predictions about world GDP and trade for this year and next year (Table 1). Under the influence of uncertainty, there are large gaps between pessimistic and optimistic forecasts. For water supply chains, uncertainty also means risks. Retailers' attitudes towards risks, namely, risk preferences, are unavoidable topics.

1.2. Aims. Owing to the background above, this paper focuses on the decision-making optimization of the riskseeking retailer managed inventory mode under stochastic demand in a water supply chain, which consists of one supplier and one retailer. Based on model assumptions, the profit expressions of supplier, retailer, and the entire water supply chain are firstly provided. Then, sensitivity analyses of related factors are given through analytical equations combined with figures. The conclusions are drawn finally.

1.3. Literature Review. Based on the background discussed in the Introduction, our study involves three aspects of literature. The first stream is about the research on water supply chains, the second one is on the retailer managed inventory with stochastic demand, and the third one is on risk preferences in inventory management.

Regarding the first stream, the water footprint theory proposed by professor Hoekstra [5] provided an effective accounting and evaluation tool for the research of water security strategy, which has become one of the hot spots in the field of water resources management. Based on this theory, water was regarded as one of the evaluation indexes of a certain agricultural or industrial supply chain [6-9], instead of being regarded as a complete supply chain. There are relatively few studies on water resources as a complete supply chain. Garcia-Caceres et al. [10] considered drinking water as a supply chain. A decision support system is presented to explore an optimal plan in order to promote the efficiency and sustainability in a drinking water treatment chain. Du et al. [11] studied the efficiency of water supply chain members under two-divided contracts of pricing and wholesale price considering different competition intensities and rainfall utilization performance degrees. In the literature of Chen and Wang [12], the operational strategy and policy for internal incentives and subsidy in a water-saving service supply chain under the scenario with maximum social welfare are discussed. Chen and Chen [13] developed, analyzed, and compared four decision models of game theory in two cases of considering or without considering backlogging for the interbasin water transfer supply chain. Loss of water transport in the condition of joint pricing and stock management is considered. By reading relevant literature, we summarize and condense the following noteworthy characteristics of water supply chains:

(1) Water supply chain is characterized by high risk and multiple risks. It is obviously affected not only by climate [14] but also by human behavior [15].

(2) Water resources can form a supply chain independently [16] or a compound supply chain with other supply chains $[17,18]$.

(3) Because of the special form of water, it is transported in one direction through prebuilt pipes and is very dependent on the infrastructure.

(4) Water supply chain is characterized by regionalization and this characteristic is also obvious for risks in water supply chains $[19,20]$.

Inventory level is one of the important indicators reflecting economic benefits of enterprises. Many scholars have proved that RMI is an inevitable inventory management mode, and, in some cases, it has certain advantages. For example, Li et al. [21] through comparative studies verified that the operation efficiency of supply chains under the VMI mode is not necessarily superior to the RMI mode in any case, and the contracts that are applicable to the RMI mode are not necessarily equally applicable to the VMI mode. Anand et al. [22] proved that, in reality, retailers may hold and manage inventory in equilibrium as strategic inventory and suppliers are unable to prevent this. Hong and Park [23] compared the policies between RMI and VMI and found that the total cost of supply chain under VMI is sometimes higher than that in the traditional RMI mode. Li et al. [24] developed a scattered supply chain for two products with the retailer as Stackelberg leader. By comparing three models, the authors arrived at the conclusion that it is optimal to offer retail-sponsored gift cards in such a supply chain. Therefore, the research on the RMI mode has important practical significance.

Because of uncertainty, the assumption of stochastic demand is more practical and representative for reality than that of deterministic demand [25]. The stochastic model can more clearly explain the demand uncertainty and is closer to the present research and practice [26]. Many researches are conducted based on the stochastic demand hypothesis. A strict policy for carbon emissions considering partial backorders is explored by Ghosh et al. [27] in order to determine the optimal strategy, including order quantity, reorder point, and shipment number in a two-stage supply chain with stochastic demand. Chan et al. [28] proposed three models of synchronized cycles under stochastic customer demand and found that the total expected cost in the stochastic synchronous cycles model is better than that under the other stochastic policies. The inventory and routing decisions of supplier are studied by Onggo et al. [29] in order to minimize the costs for inventory, transportation, food-waste, and stockout of perishable products under customers' 


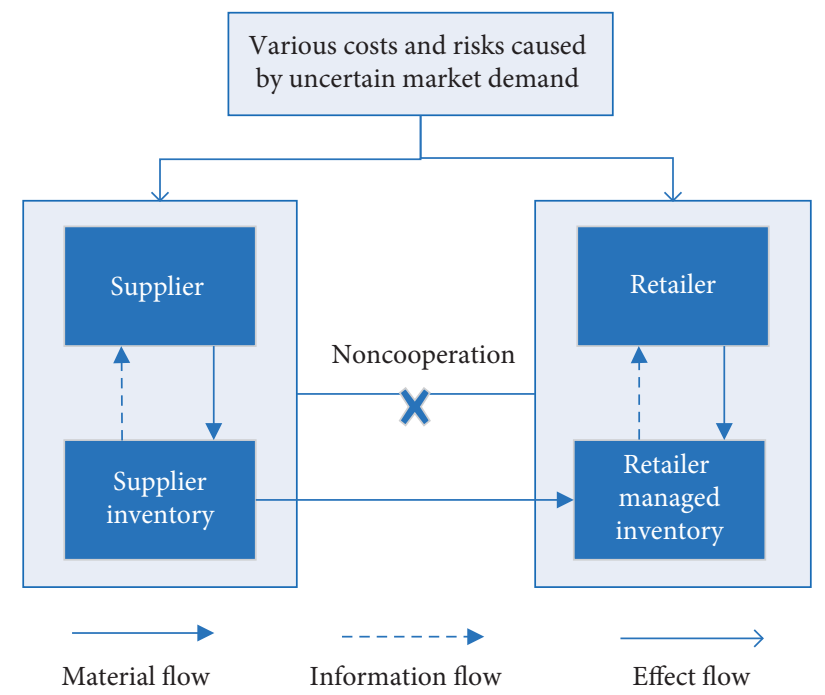

Figure 1: Schematic diagram of RMI mode.

TABLe 1: The recently updated forecasts for world Gross Domestic Product (GDP) and trade.

\begin{tabular}{|c|c|c|c|c|c|c|}
\hline & \multicolumn{2}{|c|}{$\begin{array}{l}\text { Real GDP } \\
(\% \text { change })\end{array}$} & \multicolumn{2}{|c|}{$\begin{array}{l}\text { Trade volume } \\
\text { (\% change) }\end{array}$} & \multicolumn{2}{|c|}{ Elasticity (ratio) } \\
\hline & 2020 & 2021 & 2020 & 2021 & 2020 & 2021 \\
\hline \multicolumn{7}{|l|}{ Forecast for WTO Trade (April 2020) } \\
\hline Optimistic scenario & -2.5 & 7.4 & -12.9 & 21.3 & 5.3 & 2.9 \\
\hline Pessimistic scenario & -8.8 & 5.9 & -31.9 & 24.0 & 3.6 & 4.1 \\
\hline World Economic Prospects of the IMF (April 2020) & -3.0 & 5.8 & -11.0 & 8.4 & 3.6 & 1.4 \\
\hline Global Economic Outlook of the World Bank (May 2020) & -5.2 & 4.2 & -13.4 & 5.3 & 2.6 & 1.3 \\
\hline \multicolumn{7}{|l|}{ Economic Prospects of the OECD (June 2020) } \\
\hline Single-hit scenario & -6.0 & 5.2 & -9.5 & 6.0 & 1.6 & 1.1 \\
\hline Double-hit scenario & -7.6 & 2.8 & -11.4 & 2.5 & 1.5 & 0.9 \\
\hline \multicolumn{7}{|l|}{ Memo terms } \\
\hline IMF GDP set at market exchange rate & -4.2 & 5.4 & -11.0 & 8.4 & 2.6 & 1.6 \\
\hline World Bank GDP set at purchasing power parity & -4.1 & 4.3 & -13.4 & 5.3 & 3.3 & 1.2 \\
\hline
\end{tabular}

Source: https://www.wto.org/english/news_e/pres20_e/pr858_e.htm.

stochastic demand. Chavarro et al. [30] generated and utilized 240 stochastic cases to evaluate deterministic and stochastic solution methods in the case that customer demand is considered as a normal density function. The key information for assignment decision considering customers' hierarchy is identified by Fleischmann et al. [31]. A robust and nearly optimal decentralized assignment approach is developed to fulfill the hierarchical random demand. More relevant studies can be found in the recent literature [32-34].

"Rational man" or "economic man" was assumed in the classical decision theory and caused large differences between theoretical research results and real situations. The preference and expected utility theory proposed by Von Neumann and Morgenstern [35] is the formal origin of the risk preference theory. In the inventory management area, Zanakis et al. [36] analyzed the differences between theoretical research and management practice in detail, which gradually attracted the attention of academic circles [37-39]. Related to the risk preferences in inventory management, the research on risk aversion is dominant [40-43]. For our research topic, we should also deeply explore recent literature in terms of the impact of risk preference on water supply chain. Du et al. [44] considered risk preference of water supplier and water distributor in order to study water pricing strategies in two competitive water supply chains. However, they assumed that the water supplier and water distributor were risk-neutral and acted rationally. This is the limitation of their research. Chen et al. [17] established a synthetic model system conception for a shale gas-water supply chain considering system dynamics and two-stage stochastic risk-averse programming, which generated a weight factor to measure the decision-makers' averse attitude degree towards risk. Li et al. [45], based on risk interval, proposed a stochastic optimization model aiming at many uncertainties in agricultural water resources. The application of $\mathrm{CVaR}$ and risk-aversion measures was considered. $\mathrm{Fu}$ et al. [46] contributed to the methods of water allocations by considering risk preferences of decision-makers. However, they only mentioned the level of risk-aversion. To sum up, with regard to risk preferences in water supply chain, research on risk-aversion prevails, while risk-seeking type is barely involved. The Conditional Value at Risk (CVaR) 
proposed by Rockafellar and Uryasev [47] is a common method to evaluate the degree of risks. Poormoaied and Atan [48] used CVaR to combine risk-averse and riskseeking attitudes of decision-makers. The parameters of optimal policy were obtained with maximization of the weighted utility function. Xu et al. [49] introduced CVaR into a newsvendor model and came to the conclusion that the risk-averse attitude of newsvendor facing opportunity loss may more likely cause excessive orders compared to risk-seeking attitude. Kouvelis and $\mathrm{Li}$ [50] used VaR constraints to study integrated risk management including riskseeking framework in a newsvendor setting using profit maximization.

Nevertheless, the research on water supply chains from the perspective of inventory mode and risk-seeking preference is rarely carried out in the present literature and practices. This article happens to be a useful supplement to this field.

\section{Methods}

2.1. Model Assumptions. This paper studies the inventory decision-making of a two-echelon water supply chain under the RMI mode with stochastic demand. The basic assumptions are as follows:

(1) The water supply chain is composed of one supplier and one retailer, and only the retailer is used as the main decision-making subject to study the effect of risk-seeking preference on its inventory decision. The supplier's output and inventory decisions are not controlled. Therefore, it is assumed that the supplier's ending profit is only the difference between sales revenue and production cost without supplier's inventory cost.

(2) The cost of water transportation is not considered.

(3) The retailer has only one order opportunity during the sales cycle and cannot replenish water.

(4) The wholesale price of water is determined by the supplier. The retail price of water is determined by the retailer without considering the functional relationship between price and demand.

(5) It is assumed that the market is open and there is no upper limit to the market demand. Let demand $x \in[0,+\infty)$ be a continuous random variable. Its probability density function is $f(x)$ and its cumulative distribution function is $F(x) . F(x)$ is a strictly monotonically increasing continuous function, and its inverse distribution exists, denoted as $F^{-1}(x)$. Since a specific functional form is required for sensitivity analysis, suppose that $F(x)=1-e^{-x}$, so $F^{-1}(x)=-\ln (1-x)$.

2.2. Problem Description. Based on the above assumptions, the RMI mode with stochastic demand in the water supply chain is described as follows.

In a sales cycle, the retailer orders $q$ unit water from the supplier at wholesale price $w$ and sells it to consumers at retail price $p$. Due to the uncertainty of market demand $x$, the best situation is that the retailer has an accurate understanding of market demand, the order quantity is exactly equal to the quantity demanded, and there is neither inventory cost nor shortage cost. But, in most cases, the deviation between the retailer's forecast of market demand and the actual market demand may lead to inventory costs (unit inventory cost is $h_{r}$ ) due to too many orders. At this time, at the end of the sales cycle, the retailer must deal with the remaining water at the unit residual value $r_{r}$, which is the preferential price; meanwhile, there may be shortage costs due to insufficient inventory (unit shortage cost is $b$ ).

\subsection{Optimal Decision-Making of Risk-Seeking Retailer's} Managed Inventory in the Water Supply Chain. Based on the above problem description, during the sales cycle, when the retailer's order quantity is $q$ and the market demand is $x$, the retailer's profit function in the water supply chain is as follows:

$$
\begin{aligned}
\pi_{r}(q, x)= & p \min \{q, x\}-\mathrm{wq}-h_{r}(q-x)^{+} \\
& -b(x-q)^{+}+r_{r}(q-x)^{+}
\end{aligned}
$$

where $X^{+}=\max \{0, X\}$. The first term at the right end of equation (1) represents the retailer's sales revenue and therein $\min \{q, x\}$ represents the actual sales volume of the retailer, that is, the smaller one between the quantity ordered and the quantity demanded; the second item represents its order cost; the third item represents its inventory holding cost; the fourth item represents its shortage cost when demand exceeds supply; and the last item represents its income from selling surplus water when supply exceeds demand.

Since demand $x$ is a continuous random variable, the profit described by equation (1) is also a continuous random variable. Set $Z=\pi_{r}(q, x)$; the distribution function of $Z$ is the continuous function $G(z)=P\{Z \leq z\}$. The probability density function of $Z$ is the continuous function $g(z)$, and $z$ represents the given profit level. The certain risk level $\beta \in(0,1]$ is given, and the conditional value at risk $\mathrm{CVaRT}_{\beta}(Z)$ of the profit function for the risk-seeking retailer can be expressed as

$$
\operatorname{CVaRT}_{\beta}(Z)=E\left(Z \mid Z \geq z_{\beta}\right)=\frac{1}{1-\beta} \int_{Z \geq z_{\beta}} \mathrm{zg}(z) \mathrm{d} z .
$$

That is, the conditional value at risk $\mathrm{CVaRT}_{\beta}(Z)$ of the risk-seeking retailer is used to represent the expected profit of the part, which is higher than the risk value $z_{\beta}$ on the profit function. At this point, the retailer does not control the part below the value at risk but only makes decisions on the part above the value at risk. This is the essential difference between a risk-seeking retailer and a risk-averse retailer.

In the case of retailer managed inventory under stochastic demand, the objective function of the risk-seeking retailer is

$$
\max \mathrm{CVaRT}_{\beta}(Z) \text {. }
$$

We have defined the distribution function of random profit $Z$ as a continuous function $G(z)=P\{Z \leq z\}$, where $z$ 
is the given profit level. Thus, in the case of the risk-seeking retailer managed inventory under stochastic demand, $G(z)$ is as follows.

(1) When $x \leq q$,

$$
\begin{aligned}
& P\left\{\mathrm{px}-\mathrm{wq}-h_{r}(q-x)+r_{r}(q-x) \leq z\right\} \\
& =P\left\{x \leq \frac{\left(w+h_{r}-r_{r}\right) q+z}{p+h_{r}-r_{r}}\right\} .
\end{aligned}
$$

Let $q_{1}=\left(w+h_{r}-r_{r}\right) q+z / p+h_{r}-r_{r}$ be set, denoted as

$$
G_{1}(z)=F\left(q_{1}\right)
$$

(2) When $x>q$,

$$
\begin{aligned}
& P\{\mathrm{pq}-\mathrm{wq}-b(x-q) \leq z\} \\
& =P\left\{x \geq \frac{(p-w+b) q-z}{b}\right\} .
\end{aligned}
$$

Let $q_{2}=(p-w+b) q-z / b$ be set, denoted as

$$
G_{2}(z)=1-F\left(q_{2}\right)
$$

Because of the target profit level $z \leq(p-w) q, q_{1} \leq q$ and $q_{2} \geq q$.

Now we present the relationship between the stochastic demand and profit in the case of retailer managed inventory under stochastic demand [51], as shown in Figure 2, where (a) represents the target profit level $z \leq \pi_{A}$ and (b) represents the target profit level $z \in\left(\pi_{A}, \pi_{B}\right]$ in the water supply chain.

From Figure 2, we can visually see the relationship between the retailer's profit and the stochastic demand with the fixed order quantity $q$ in the water supply chain. We assume that the market is open and that there is no upper limit to the market demand $x$. Let $x \in(0,+\infty)$ be set; therefore, the retailer's profit function is in one continuous decreasing state in the interval $(q,+\infty)$. Point A denotes the retailer's profit when the market demand $x=0$. The retailer holds the largest inventory at this point and its corresponding profit is $\pi_{A}=\left(-w-h_{r}+r_{r}\right) q$. Point $\mathrm{B}$ represents the retailer's profit when the market demand is exactly equal to the order quantity, which is also the maximum profit $\pi_{B}=$ $(p-w) q$ under the fixed order quantity. In order to further analyze the optimal inventory strategy of the risk-seeking retailer, we discuss it in the following two cases:

(1) When $z \leq \pi_{A}$ and $z=G_{2}^{-1}(\beta)$, combining equation (7), the following can be obtained:

$$
z_{\beta}=(p-w+b) q-\mathrm{bF}^{-1}(1-\beta) .
$$

Meanwhile, from $z \leq \pi_{A}$ and equation (8), the following can be obtained:

$$
q \leq \frac{\mathrm{bF}^{-1}(1-\beta)}{p+b+h_{r}-r_{r}} .
$$

(2) When $z \in\left(\pi_{A}, \pi_{B}\right]$ and $G_{1}\left(z_{\beta}\right)+G_{2}\left(z_{\beta}\right)=\beta$, combing equations (5) and (7), the following can be obtained:

$$
1+F\left(q_{1}\right)-F\left(q_{2}\right)=\beta .
$$

We get $q>\mathrm{bF}^{-1}(1-\beta) / p+b+h_{r}-r_{r}$.

Proposition 1. In the water supply chain under RMI mode with stochastic demand, the risk-seeking retailer takes CVaRprofit maximization as its decision-making objective and its optimal inventory quantity $Q^{*}$ is as follows:

(1) When $q \leq b F^{-1}(1-\beta) / p+b+h_{r}-r_{r}$,

$$
Q^{*}= \begin{cases}F^{-1}\left((1-\beta) \frac{p-w+b}{p+h_{r}+b-r_{r}}\right)-x, & q^{*}>x \\ 0, & q^{*} \leq x .\end{cases}
$$

(2) When $q>b F^{-1}(1-\beta) / p+b+h_{r}-r_{r}$ and $f(q)$ $>b\left(w+h_{r}-r_{r}\right)^{2} f\left(q_{1}\right)+\left(p+h_{r}-r_{r}\right)(p-w+b)^{2} f$ $\left(q_{2}\right) / b\left(p+h_{r}-r_{r}\right)\left(p+h_{r}+b-r_{r}\right)$,

$$
Q^{*}= \begin{cases}\left(p+b+h_{r}-r_{r}\right)^{-1}\left(\begin{array}{cc}
\left(p+h_{r}-r_{r}\right) F^{-1}\left(F\left(q^{*}\right)-\frac{(p-w+b)(1-\beta)}{\left(p+h_{r}+b-r_{r}\right)}\right) \\
+b F^{-1}\left(F\left(q^{*}\right)+\frac{\left(w+h_{r}-r_{r}\right)(1-\beta)}{p+h_{r}+b-r_{r}}\right)
\end{array}\right)-x, \quad q^{*}>x \\
0, & q^{*} \leq x .\end{cases}
$$




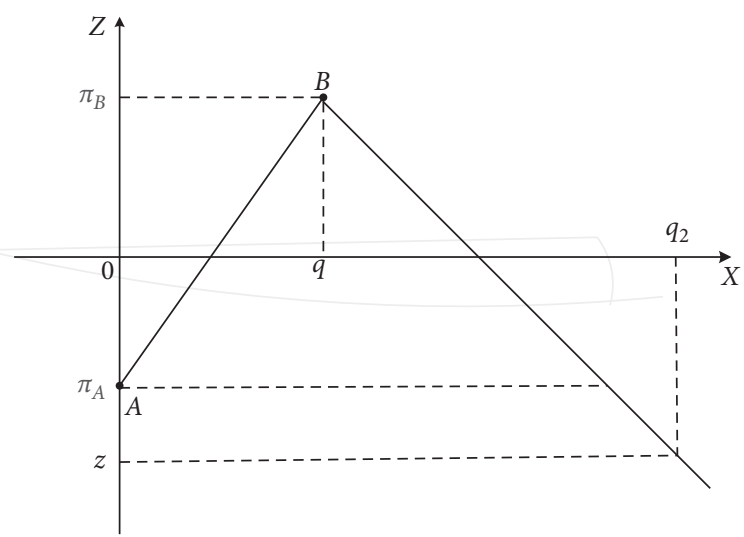

(a)

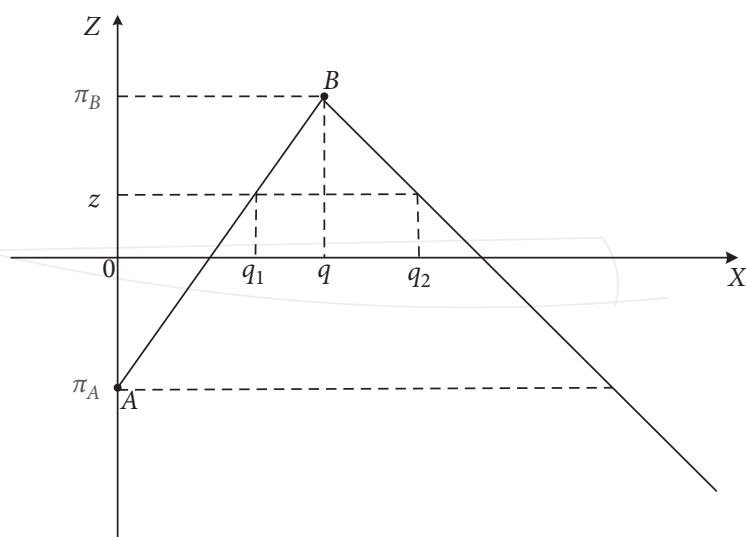

(b)

Figure 2: Schematic diagram of the relationship between stochastic demand and profit under the risk-seeking retailer managed inventory mode in the water supply chain. (a) $z \leq \pi_{A}$. (b) $z \in\left(\pi_{A}, \pi_{B}\right]$.

Proof. Based on the groundwork mentioned above, the solution process is divided into the two following situations:

(1) When $q \leq \mathrm{bF}^{-1}(1-\beta) / p+b+h_{r}-r_{r}, z_{\beta}=(p-w+$ b) $q-\mathrm{bF}^{-1}(1-\beta)$. By observing Figure 2 , when $z=z_{\beta}$, the corresponding demand is $F^{-1}(1-\beta)$. According to the definition formula (2) of the Conditional Value at Risk-seeking $\mathrm{CVaRT}_{\beta}(Z)$, we can draw that the retailer does not make decisions on the worst profit in the demand interval $\left[F^{-1}(1-\right.$ $\beta$ ), $+\infty$ ] (the profit possibility of this part is $\beta$ ) but only controls the demand interval $\left[0, F^{-1}(1-\beta)\right]$ corresponding to the stochastic profit $z \geq z_{\beta}$. In this case, formula (2) is equivalent to

$$
\operatorname{CVaRT}_{\beta}(Z)=\frac{1}{1-\beta}\left(\begin{array}{c}
\int_{0}^{q}\left[\left(p+h_{r}-r_{r}\right) t-\left(w+h_{r}-r_{r}\right) q\right] \mathrm{d} F(t) \\
+\int_{q}^{F^{-1}(1-\beta)}[(p-w+b) q-b t] \mathrm{d} F(t)
\end{array}\right)
$$

Solving the first partial derivative of the above equation with respect to order quantity $q$, we can obtain

$$
\begin{aligned}
\frac{\partial \operatorname{CVaRT}_{\beta}(Z)}{\partial q}= & \frac{1}{1-\beta}\left(-\left(p+h_{r}+b-r_{r}\right) F(q)\right. \\
& +(p-w+b)(1-\beta)) .
\end{aligned}
$$

We have

$$
\frac{\partial^{2} \operatorname{CVaRT}_{\beta}(Z)}{\partial q^{2}}=\frac{1}{1-\beta}\left(-\left(p+h_{r}+b-r_{r}\right) f(q)\right)<0
$$

Therefore, the maximum exists. The optimal order quantity can be obtained by setting the first-order condition equal to 0 :

$$
q^{*}=F^{-1}\left((1-\beta) \frac{p-w+b}{p+h_{r}+b-r_{r}}\right)
$$

(2) When $q>\mathrm{bF}^{-1}(1-\beta) / p+b+h_{r}-r_{r}, z_{\beta}$ satisfies $1+F\left(q_{1}\right)-F\left(q_{2}\right)=\beta$. Similarly, by observing Figure 2 , we can obtain that the retailer only controls the demand segment $\left[q_{1}, q_{2}\right]$ corresponding to the stochastic profit $z \geq z_{\beta}$. At this point, equation (2) is equivalent to 


$$
\operatorname{CVaRT}_{\beta}(Z)=\frac{1}{1-\beta}\left(\begin{array}{c}
\int_{q_{1}}^{q}\left[\left(p+h_{r}-r_{r}\right) t-\left(w+h_{r}-r_{r}\right) q\right] \mathrm{d} F(t) \\
+\int_{q}^{q_{2}}[(p-w+b) q-\mathrm{bt}] \mathrm{d} F(t)
\end{array}\right) .
$$

Solving the first partial derivative of the above equation with respect to order quantity $q$, we can get

$$
\frac{\partial \operatorname{CVaRT}_{\beta}(Z)}{\partial q}=\frac{1}{1-\beta}\left(-\left(p+h_{r}+b-r_{r}\right) F(q)+\left(w+h_{r}-r_{r}\right) F\left(q_{1}\right)+(p-w+b) F\left(q_{2}\right)\right) .
$$

where

$$
\frac{\partial^{2} \operatorname{CVaRT}_{\beta}(Z)}{\partial q^{2}}=\frac{1}{1-\beta}\left(-\left(p+h_{r}+b-r_{r}\right) f(q)+\frac{\left(w+h_{r}-r_{r}\right)^{2}}{p+h_{r}-r_{r}} f\left(q_{1}\right)+\frac{(p-w+b)^{2}}{b} f\left(q_{2}\right)\right)
$$

The sign symbol of the above equation cannot be judged by the existing conditions, so we use the inverse method to solve it. Assuming that when $q>\mathrm{bF}^{-1}(1-\beta) / p+b+h_{r}-r_{r}$, the maximum exists,

$$
\frac{\partial^{2} C V a R T_{\beta}(Z)}{\partial q^{2}}<0
$$

that is, $f(q)>b\left(w+h_{r}-r_{r}\right)^{2} f\left(q_{1}\right)+\left(p+h_{r}-r_{r}\right)(p-w+$ $b)^{2} f\left(q_{2}\right) / b\left(p+h_{r}-r_{r}\right)\left(p+h_{r}+b-r_{r}\right)$ holds.

Let the first-order condition be 0 ; combining the equation $z=\left(p+h_{r}-r_{r}\right) q_{1}-\left(w+h_{r}-r_{r}\right) q=(p-w+b)$ $q-b q_{2}$ and equation (10), we get the optimal order quantity *:

$$
q^{*}=\frac{\left(p+h_{r}-r_{r}\right) F^{-1}\left(F\left(q^{*}\right)-\left((p-w+b)(1-\beta) /\left(p+h_{r}+b-r_{r}\right)\right)\right)+b F^{-1}\left(F\left(q^{*}\right)+\left(\left(w+h_{r}-r_{r}\right)(1-\beta) / p+h_{r}+b-r_{r}\right)\right)}{p+b+h_{r}-r_{r}} .
$$

In conclusion, we have the following:

(1) When $q \leq \mathrm{bF}^{-1}(1-\beta) / p+b+h_{r}-r_{r}$, the optimal order quantity $q^{*}$ of the risk-seeking retailer in the water supply chain is

$$
q^{*}=F^{-1}\left((1-\beta) \frac{p-w+b}{p+h_{r}+b-r_{r}}\right) \text {. }
$$

(2) When $q>\mathrm{bF}^{-1}(1-\beta) / p+b+h_{r}-r_{r}$ and $f(q)>$ $b\left(w+h_{r}-r_{r}\right)^{2} f\left(q_{1}\right)+\left(p+h_{r}-r_{r}\right) \quad(p-w+b)^{2}$ $f\left(q_{2}\right) / b\left(p+h_{r}-r_{r}\right)\left(p+h_{r}+b-r_{r}\right)$, the optimal order quantity $q^{*}$ of the risk-seeking retailer in the water supply chain is

$$
q^{*}=\frac{\left(p+h_{r}-r_{r}\right) F^{-1}\left(F\left(q^{*}\right)-\left((p-w+b)(1-\beta) /\left(p+h_{r}+b-r_{r}\right)\right)\right)+\mathrm{bF}^{-1}\left(F\left(q^{*}\right)+\left(\left(w+h_{r}-r_{r}\right)(1-\beta) / p+h_{r}+b-r_{r}\right)\right)}{p+b+h_{r}-r_{r}}
$$


Thus, equations (11) and (12) of the optimal inventory quantity of the retailer in the water supply chain hold. So, we can directly get Proposition 2-Proposition 5.

Proposition 2. In the case of the risk-seeking retailer managed inventory under stochastic demand scenario in the water supply chain, the optimal inventory cost $C^{*}$ of the riskseeking retailer aiming at maximizing CVaR-profit is given by

$$
C^{*}=h_{r}\left(q^{*}-x\right)^{+} \text {. }
$$

Proposition 3. In the case of the risk-seeking retailer managed inventory under stochastic demand scenario in the water supply chain, the supplier's profit can be expressed by

$$
\pi_{m}=(w-c) q^{*}
$$

Proposition 4. In the case of the risk-seeking retailer managed inventory under stochastic demand scenario in the water supply chain, the retailer's profit can be expressed by

$$
\pi_{r}=(p-w+b) q^{*}-\mathrm{bx}-\left(p+h_{r}+b-r_{r}\right)\left(q^{*}-x\right)^{+} .
$$

Proposition 5. In the case of the risk-seeking retailer managed inventory under stochastic demand scenario in the water supply chain, the profit of the entire supply chain is given by

$$
\pi_{c}=(p+b-c) q^{*}-\mathrm{bx}-\left(p+h_{r}+b-r_{r}\right)\left(q^{*}-x\right)^{+} .
$$

\section{Results and Discussion}

Then, the sensitivity of the risk-seeking retailer's optimal inventory strategy is analyzed under RMI mode with stochastic demand in the water supply chain. The effects of relevant factor changes on the retailer's inventory strategy are discussed.

Since Proposition 1 gives the optimal inventory quantity under two conditions, as shown in equations (11) and (9), in this section, we only carry out sensitivity analysis on the optimal inventory strategy when $x<q^{*}$ $\leq \mathrm{bF}^{-1}(1-\beta) / p+b+h_{r}-r_{r}$, as shown in Corollaries 1 and 2 .

Corollary 1. In the case of the risk-seeking retailer managed inventory under stochastic demand scenario in the water supply chain, when $x<q^{*} \leq b F^{-1}(1-\beta) / p+b+h_{r}-r_{r}$, the optimal inventory quantity $Q^{*}$ of the risk-seeking retailer increases monotonously with respect to the retail price $p$, unit shortage cost $b$, and unit residual value $r_{r}$, while it decreases monotonously with respect to the wholesale price $w$ and unit inventory cost $h_{r}$.

Proof. Solving the partial derivatives of the optimal inventory quantity $Q^{*}$ with respect to the retail price $p$, wholesale price $w$, unit shortage cost $b$, unit inventory cost $h_{r}$ and unit residual value $r_{r}$ in equation (11), we can obtain

$$
\begin{aligned}
& \frac{\partial Q^{*}}{\partial p}=\frac{1}{f\left[F^{-1}(1-\beta)\left(p-w+b / p+h_{r}+b-r_{r}\right)\right]}(1-\beta) \frac{h_{r}+w-r_{r}}{\left(p+h_{r}+b-r_{r}\right)^{2}} \geq 0, \\
& \frac{\partial Q^{*}}{\partial w}=-\frac{1}{f\left[F^{-1}(1-\beta)\left(p-w+b / p+h_{r}+b-r_{r}\right)\right]}(1-\beta) \frac{1}{p+h_{r}+b-r_{r}} \leq 0, \\
& \frac{\partial Q^{*}}{\partial b}=\frac{1}{f\left[F^{-1}(1-\beta)\left(p-w+b / p+h_{r}+b-r_{r}\right)\right]}(1-\beta) \frac{h_{r}+w-r_{r}}{\left(p+h_{r}+b-r_{r}^{2}\right)} \geq 0, \\
& \frac{\partial Q^{*}}{\partial h_{r}}=-\frac{1}{f\left[F^{-1}(1-\beta)\left(p-w+b / p+h_{r}+b-r_{r}\right)\right]}(1-\beta) \frac{w-p-b}{\left(p+h_{r}+b-r_{r}\right)^{2}} \leq 0, \\
& \frac{\partial Q^{*}}{\partial r_{r}}=\frac{1}{f\left[F^{-1}(1-\beta)\left(p-w+b / p+h_{r}+b-r_{r}\right)\right]}(1-\beta) \frac{p+b-w}{\left(p+h_{r}+b-r_{r}\right)^{2}} \geq 0 .
\end{aligned}
$$

To sum up, the following conclusions are valid: 


$$
\begin{aligned}
& \frac{\partial Q^{*}}{\partial p} \geq 0, \\
& \frac{\partial Q^{*}}{\partial w} \leq 0, \\
& \frac{\partial Q^{*}}{\partial b} \geq 0, \\
& \frac{\partial Q^{*}}{\partial h_{r}} \leq 0, \\
& \frac{\partial Q^{*}}{\partial r_{r}} \geq 0 .
\end{aligned}
$$

In other words, Corollary 1 is valid.

Corollary 1 shows that the risk level has no effect on the monotonicity of the optimal inventory quantity in the five dimensions of the retail price, wholesale price, unit shortage cost, unit inventory cost, and unit residual value in the water supply chain. But, from Figure 3-7, we can see that, under different risk levels, the retail price, wholesale price, unit shortage cost, unit inventory cost, and unit residual value have different effect strengths on the optimal inventory quantity. When the retail price, unit shortage cost, and unit residual value increase, the risk-seeking retailer's optimal inventory quantity also increases, as shown in Figures 3-5 and Figures 8-10. On the contrary, when the wholesale price and unit inventory cost increase, the optimal inventory quantity decreases, as shown in Figures $6,7,11$, and 12 .

Corollary 2. In the water supply chain, when $x<q^{*} \leq b F^{-1}$ $(1-\beta) / p+b+h_{r}-r_{r}$, the optimal inventory cost $C^{*}$ of the risk-seeking retailer under RMI mode with stochastic demand increases monotonously with respect to the retail price $p$, unit shortage cost $b$, and unit residual value $r_{r}$, while it decreases monotonously with respect to the wholesale price $w$. When $0<h_{r} \leq Q^{*} / B,{ }_{C}^{*}$ increases monotonously with respect to the unit inventory cost $h_{r}$; when $h_{r}>Q^{*} / B, C^{*}$ decreases monotonously with respect to the unit inventory cost $h_{r}$.

Proof. Because the proof process is similar to that of Corollary 1 , we do not repeat it here and only give a brief analysis and figures. When $x<q^{*} \leq \mathrm{bF}^{-1}(1-\beta) / p+b+h_{r}-r_{r}$, solving the partial derivatives of the optimal inventory cost $C^{*}$ with respect to the retail price $p$, wholesale price $w$, unit shortage price $b$, unit residual value $r_{r}$, and unit inventory cost $h_{r}$ in equation (24), we can obtain

$$
\begin{aligned}
& \frac{\partial C^{*}}{\partial p} \geq 0, \\
& \frac{\partial C^{*}}{\partial w} \leq 0, \\
& \frac{\partial C^{*}}{\partial b} \geq 0, \\
& \frac{\partial C^{*}}{\partial r_{r}} \geq 0, \\
& \frac{\partial C^{*}}{\partial h_{r}}=Q^{*}-h_{r} \frac{(1-\beta)(p-w+b)}{\left(p+h_{r}+b-r_{r}\right)^{2} f\left(F^{-1}\left((1-\beta)\left(p-w+b / p+h_{r}+b-r_{r}\right)\right)\right)} .
\end{aligned}
$$

Let $B=(1-\beta)(p-w+b) /\left(p+h_{r}+b-r_{r}\right)^{2} f\left(F^{-1}((1-\right.$ B) $\left.\left.\left(p-w+b / p+h_{r}+b-r_{r}\right)\right)\right)$ be set;

Thus, $B>0$, where $\partial C^{*} / \partial h_{r}=Q^{*}-h_{r} B$.

Because it is not easy to judge the sign symbol on the right side of the equation, we discuss it in the two following cases:

(1) When $0<h_{r} \leq Q^{*} / B$, it is easy to get $\partial C^{*} / \partial h_{r} \geq 0$

(2) When $h_{r}>Q^{*} / B$, it is easy to get $\partial C^{*} / \partial h_{r}<0$

That is, Corollary 2 holds.

Corollary 2 shows that the risk level has no effect on the monotonicity of the optimal inventory cost in the five dimensions of the retail price, wholesale price, unit shortage cost, unit inventory cost, and unit residual value. But, from Figure 13-17, we can see that, under different risk levels, the retail price, wholesale price, unit shortage cost, unit inventory cost, and unit residual value have different effect strengths on the optimal inventory cost. When the retail price, unit shortage cost, and unit residual value increase, the risk-seeking retailer's optimal inventory cost also increases, as shown in Figures 13-15 and Figure 18-20. On the contrary, when the wholesale price increases, the optimal inventory cost decreases, as shown in Figure 16 and Figure 21 . When $0<h_{r} \leq Q^{*} / B$, the optimal inventory cost increases with the increase of the unit inventory cost; when $h_{r}>Q^{*} / B$, the optimal inventory cost decreases with the increase of the unit inventory cost, as shown in Figures 17 and 22. 


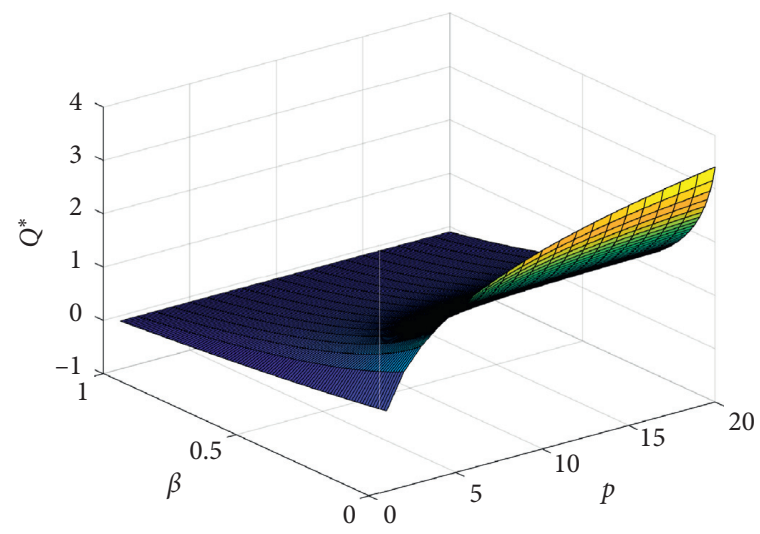

FIGURE 3: Effect of risk level $\beta$ and retail price $p$ on the optimal inventory quantity $Q^{*}$ under RMI mode with stochastic demand in the water supply chain.

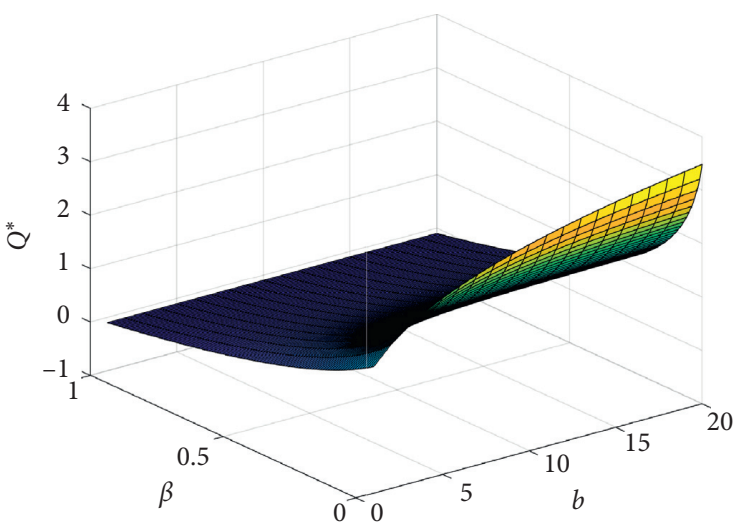

Figure 4: Effect of risk level $\beta$ and unit shortage cost $b$ on the optimal inventory quantity $Q^{*}$ under RMI mode with stochastic demand in the water supply chain.

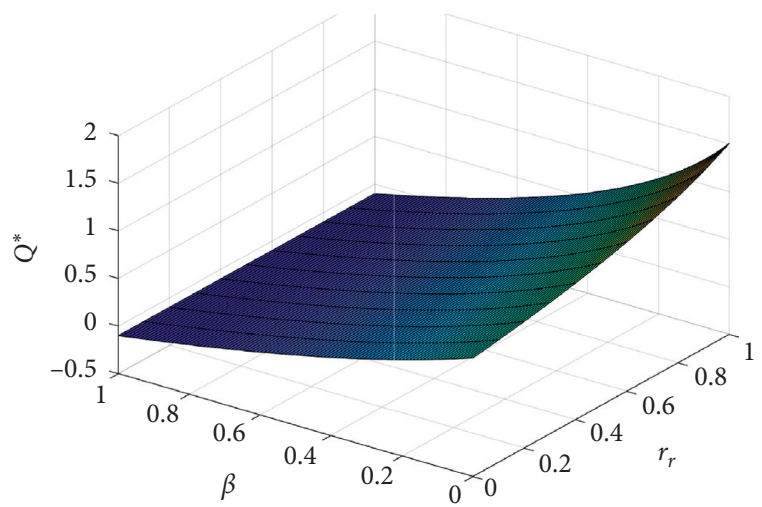

Figure 5: Effect of risk level $\beta$ and unit residual value $r_{r}$ on the optimal inventory quantity $Q^{*}$ under RMI mode with stochastic demand in the water supply chain.

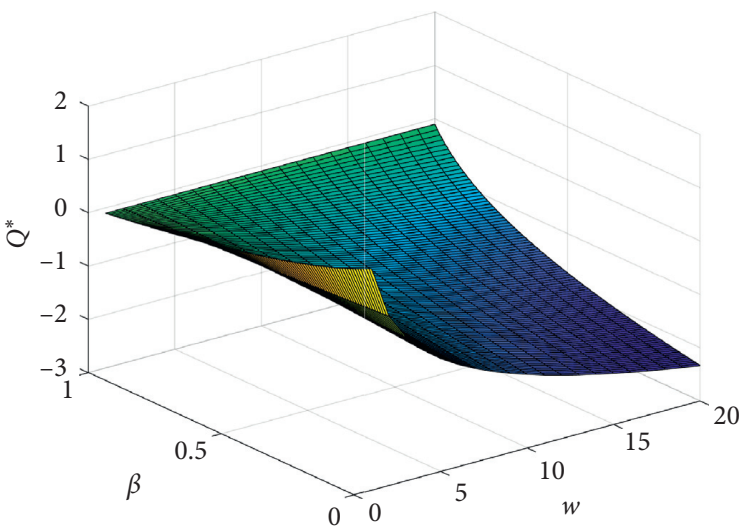

Figure 6: Effect of risk level $\beta$ and wholesale price $w$ on the optimal inventory quantity $Q^{*}$ under RMI mode with stochastic demand in the water supply chain.

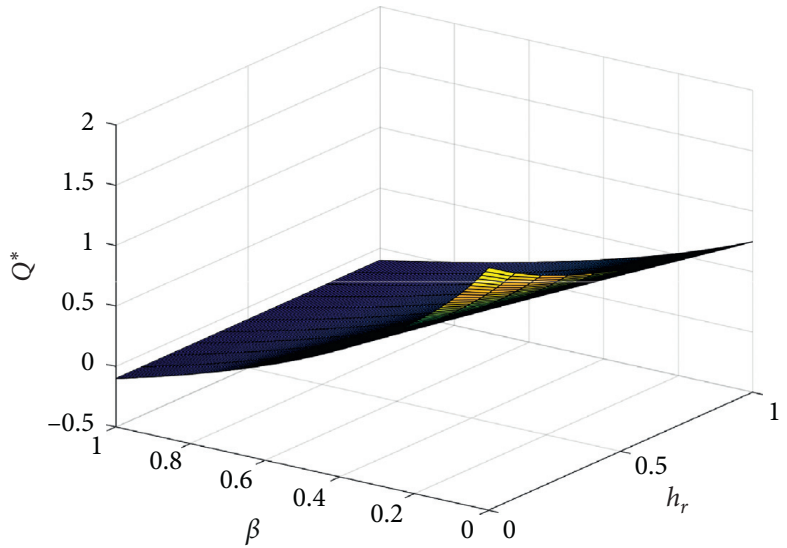

FIGURE 7: Effect of risk level $\beta$ and unit inventory cost $h_{r}$ on the optimal inventory quantity $Q^{*}$ under RMI mode with stochastic demand in the water supply chain.

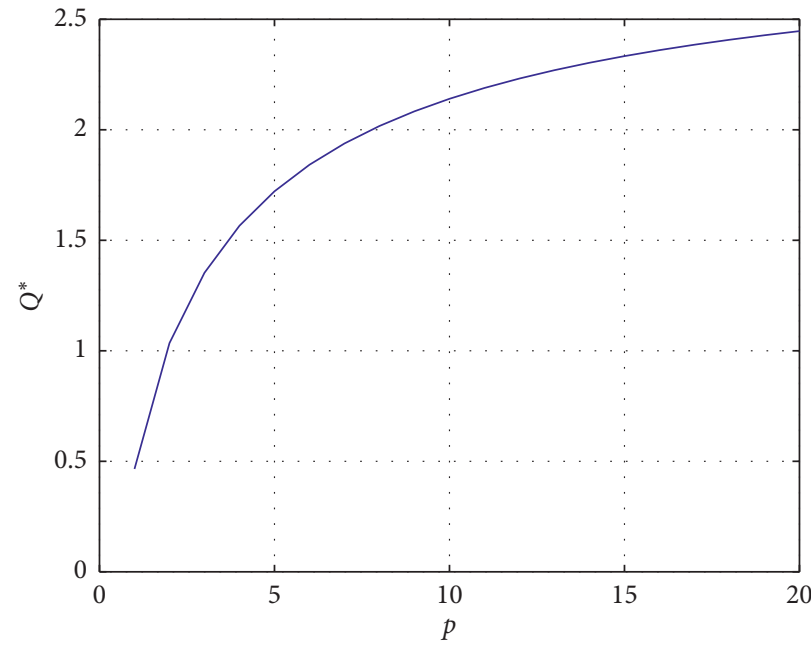

FIGURE 8: Effect of retail price $p$ on the optimal inventory quantity $Q^{*}$ under RMI mode with stochastic demand in the water supply chain. 


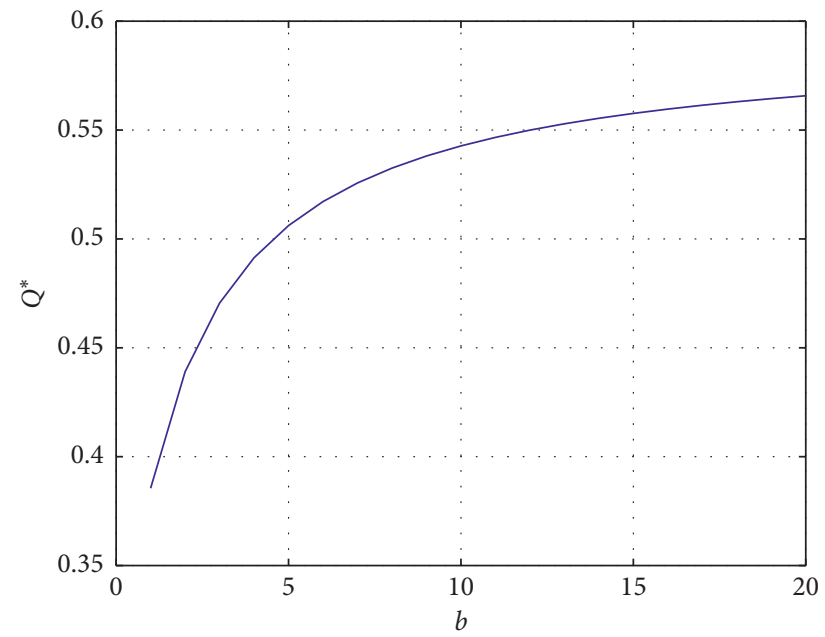

FIGURE 9: Effect of unit shortage cost $b$ on the optimal inventory quantity $Q^{*}$ under RMI mode with stochastic demand in the water supply chain.

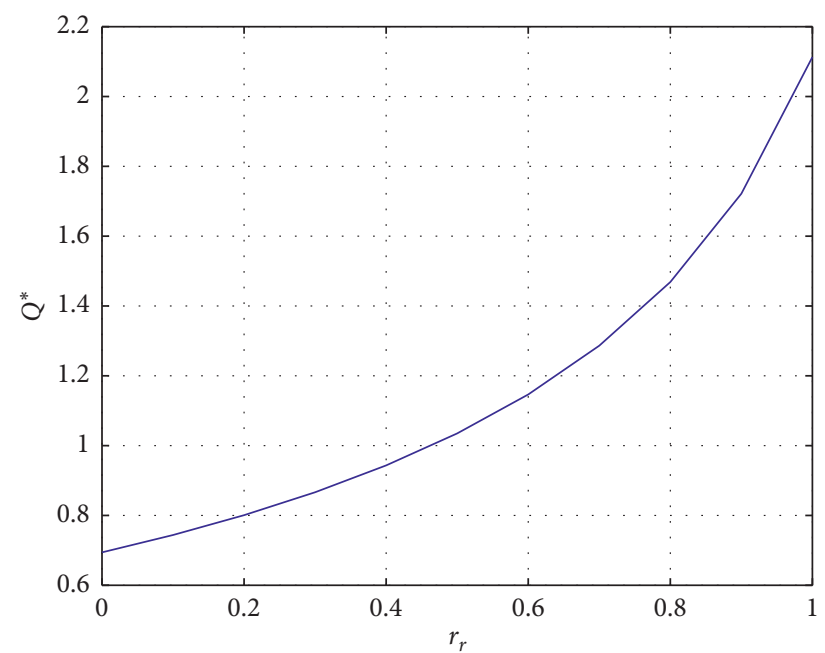

FIGURE 10: Effect of unit residual value $r_{r}$ on the optimal inventory quantity $Q^{*}$ under RMI mode with stochastic demand in the water supply chain.

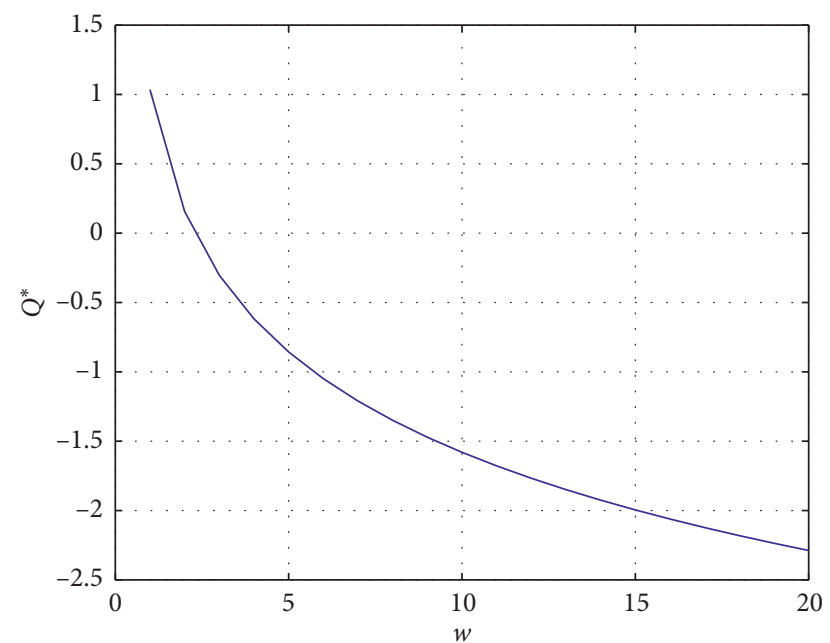

FIGURE 11: Effect of wholesale price $w$ on the optimal inventory quantity $Q^{*}$ under RMI mode with stochastic demand in the water supply chain. 


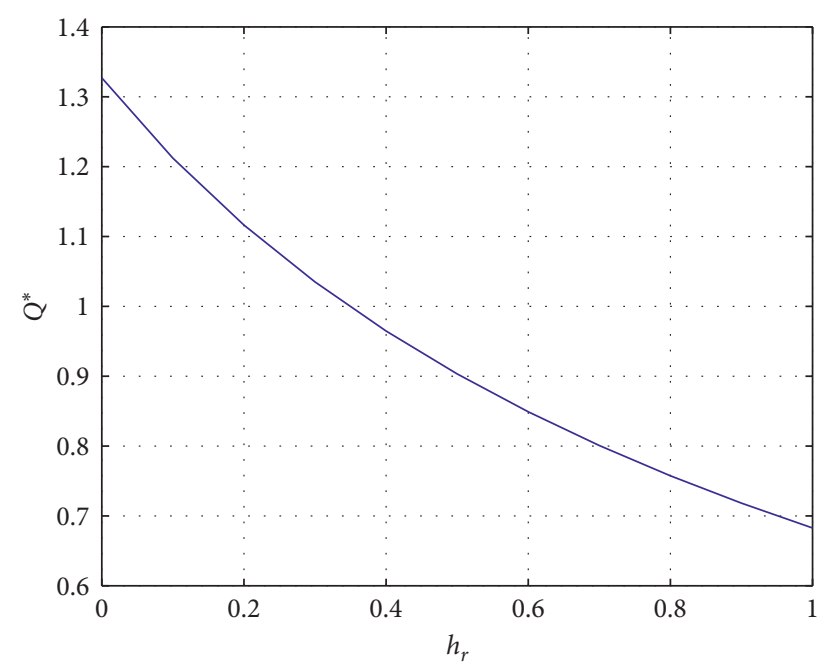

FIGURE 12: Effect of unit inventory cost $h_{r}$ on the optimal inventory quantity $Q^{*}$ under RMI mode with stochastic demand in the water supply chain.

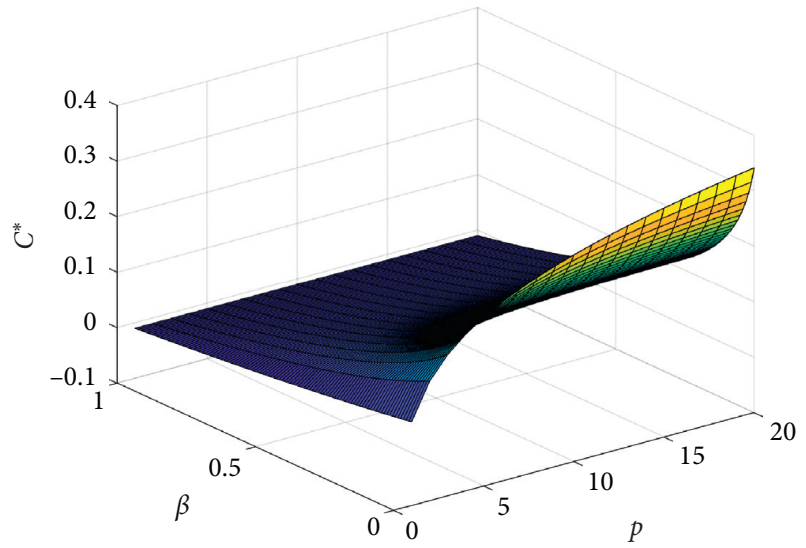

FIGURE 13: Effect of risk level $\beta$ and retail price $p$ on the optimal inventory cost $C^{*}$ under RMI mode with stochastic demand in the water supply chain.

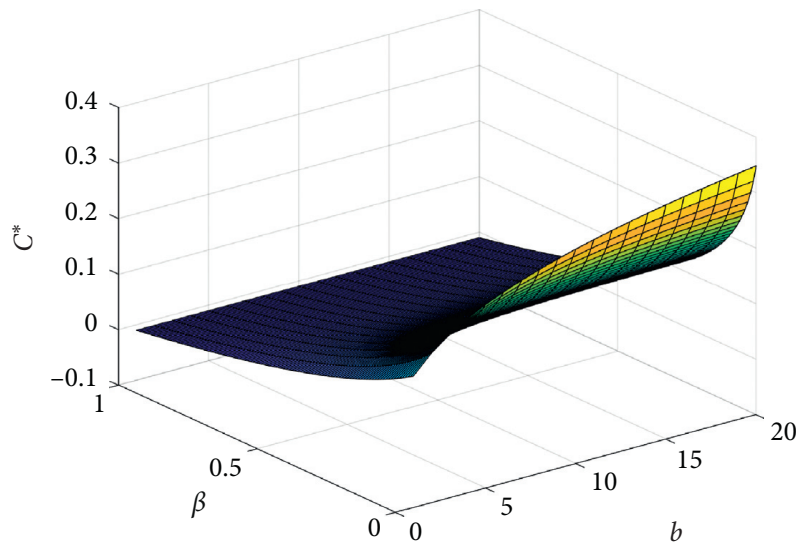

FIGURE 14: Effect of risk level $\beta$ and unit shortage cost $b$ on the optimal inventory cost $C^{*}$ under RMI mode with stochastic demand in the water supply chain. 


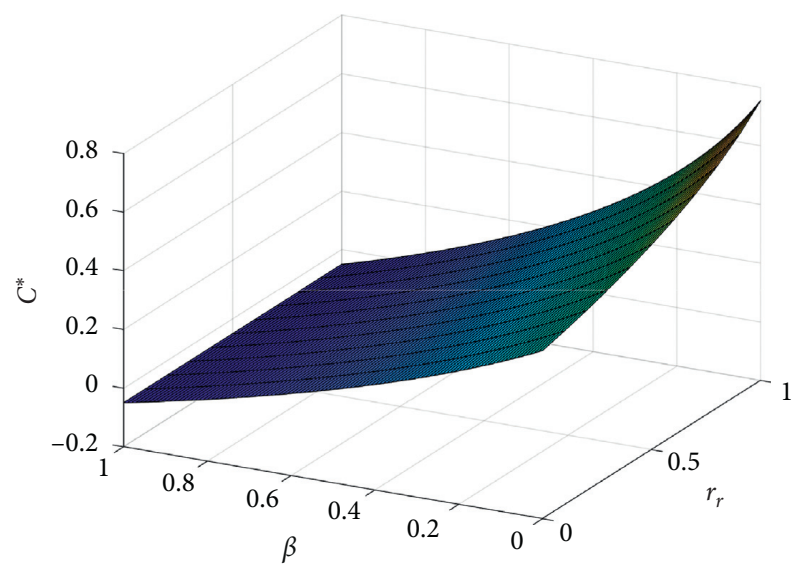

FIgURE 15: Effect of risk level $\beta$ and unit residual value $r_{r}$ on the optimal inventory cost $C^{*}$ under RMI mode with stochastic demand in the water supply chain.

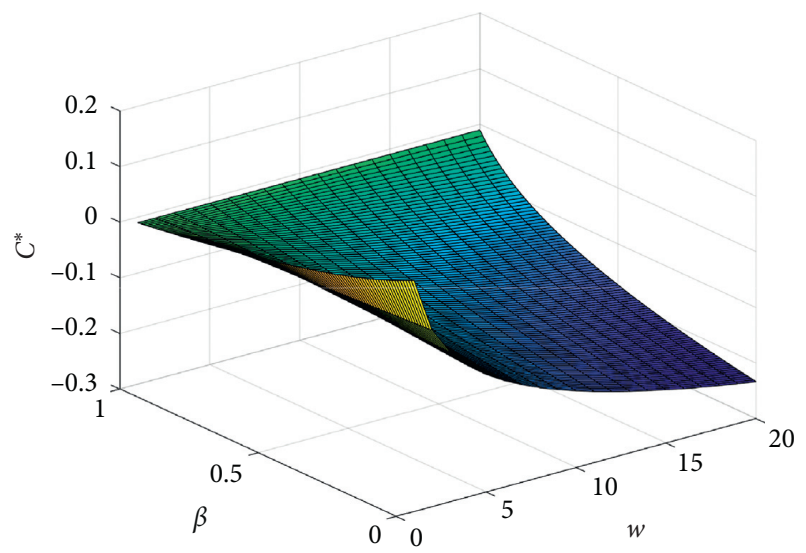

FIGURE 16: Effect of risk level $\beta$ and wholesale price $w$ on the optimal inventory cost $C^{*}$ under RMI mode with stochastic demand in the water supply chain.

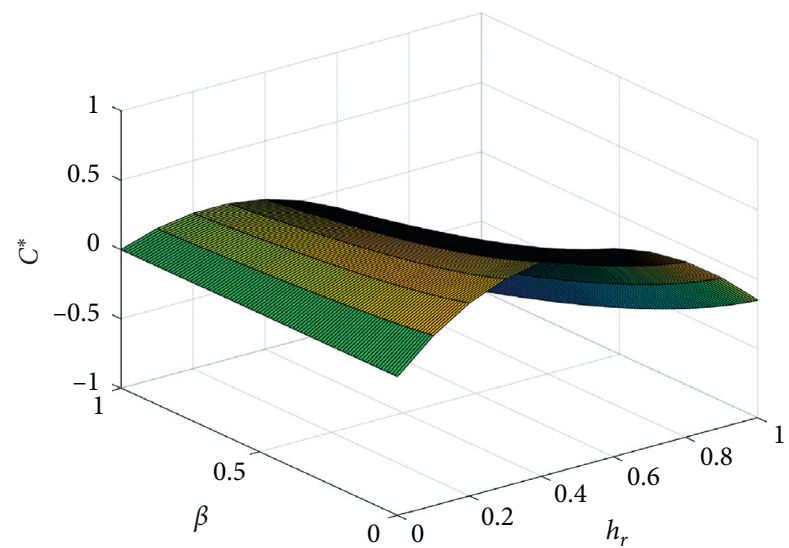

FIGURE 17: Effect of risk level $\beta$ and unit inventory cost $h_{r}$ on the optimal inventory cost $C^{*}$ under RMI mode with stochastic demand in the water supply chain. 


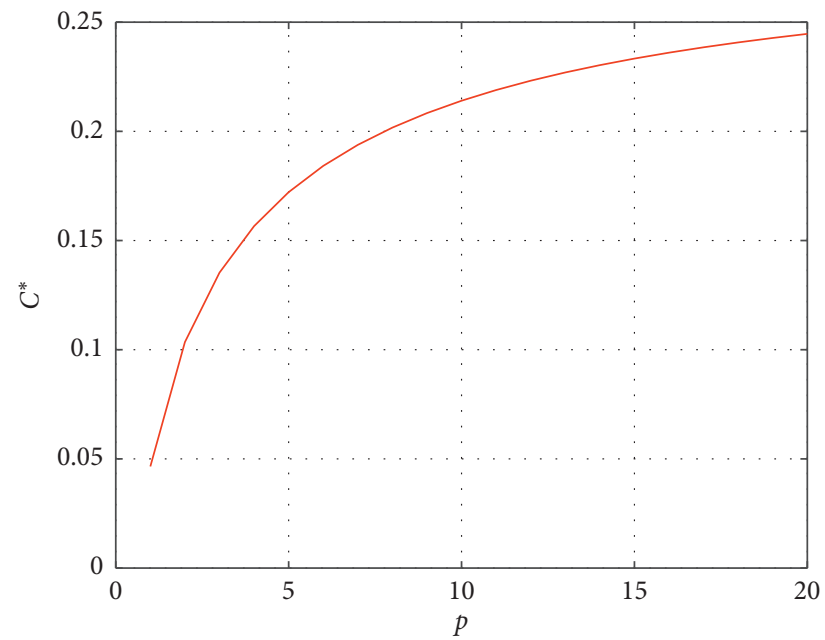

FIGURE 18: Effect of retail price $p$ on the optimal inventory cost $C^{*}$ under RMI mode with stochastic demand in the water supply chain.

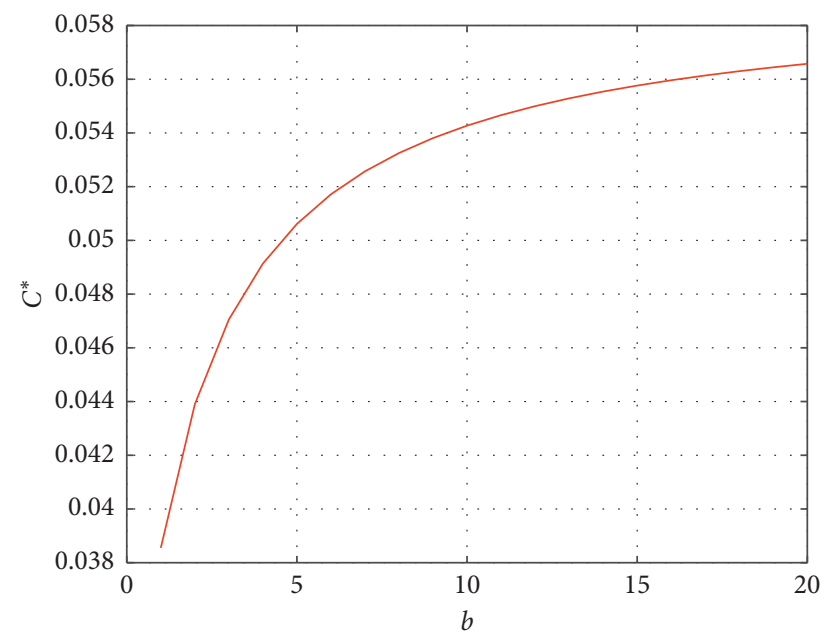

FIGURE 19: Effect of unit shortage cost $b$ on the optimal inventory cost $C^{*}$ under RMI mode with stochastic demand in the water supply chain.

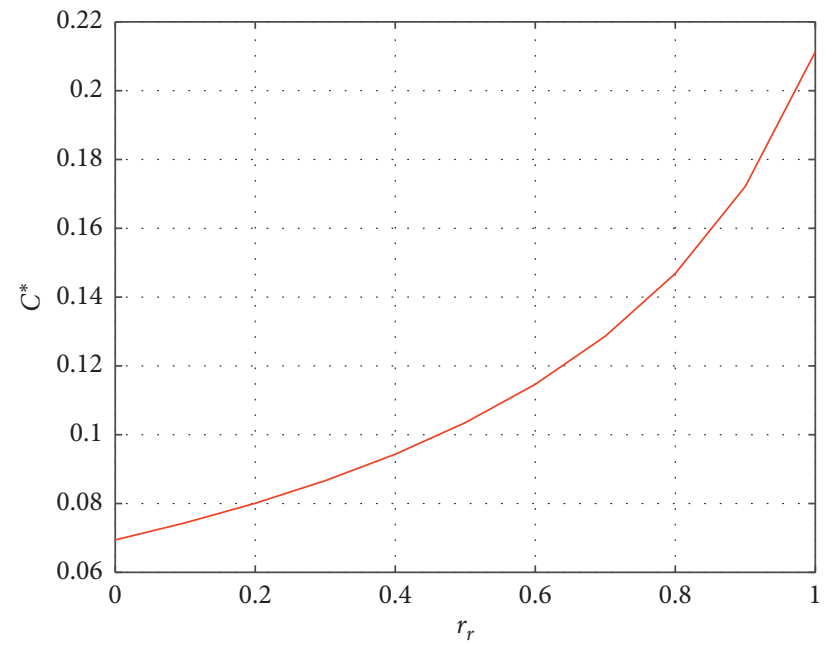

FIGURE 20: Effect of unit residual value $r_{r}$ on the optimal inventory cost $C^{*}$ under RMI mode with stochastic demand in the water supply chain. 


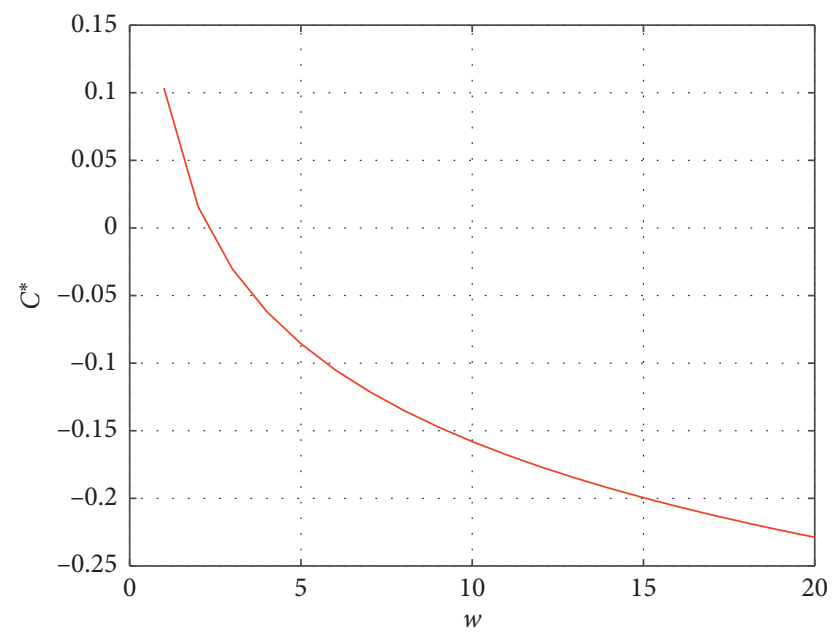

FIGURE 21: Effect of wholesale price $w$ on the optimal inventory cost $C^{*}$ RMI mode with stochastic demand under in the water supply chain.

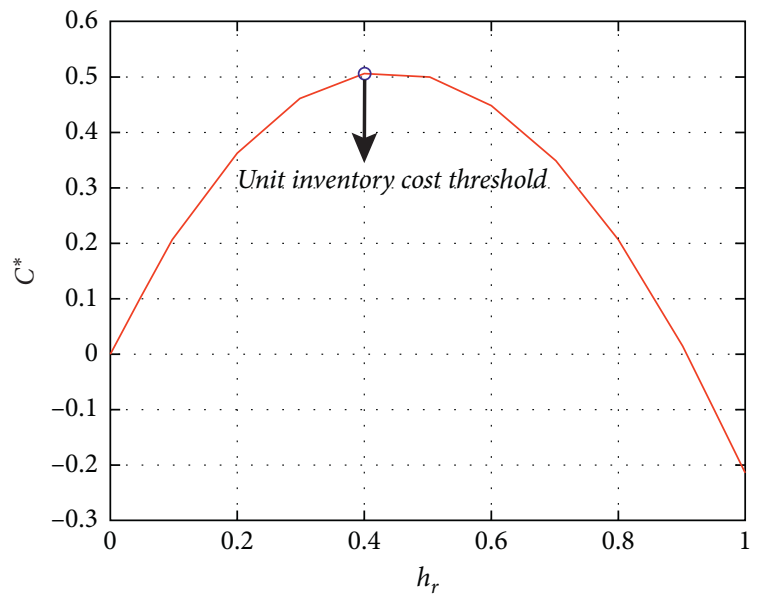

FIGURE 22: Effect of unit inventory cost $h_{r}$ on the optimal inventory cost $C^{*}$ under RMI mode with stochastic demand in the water supply chain.

\section{Conclusions}

Water supply chain is characterized by high risk and multiple risks. The decision-maker's attitude to risk is one of the important factors that affect the decision result. Uncertain demand is the most fundamental uncertainty in supply chains. So, stochastic demand is incorporated into our research hypothesis. Based on the model assumptions, we study the optimal decisions of the risk-seeking retailer under RMI mode considering stochastic demand in a water supply chain. Firstly, we discussed the relationship between stochastic demand and profit. Next, we proved the expressions of the risk-seeking retailer's optimal inventory quantity, and then the expression of the risk-seeking retailer's optimal inventory cost, the profit expressions of the supplier, retailer, and the entire supply chain are derived. Finally, through sensitivity analysis and numerical simulation, we explored the impact of risk level on the optimal inventory decisions. We get the following conclusions:
(1) In the water supply chain, the risk-seeking level has no effect on the monotonicity of the optimal inventory quantity and optimal inventory cost in the five dimensions of the retail price, wholesale price, unit shortage cost, unit inventory cost, and unit residual value. But, under different risk levels, the five dimensions generate different effect strengths on the optimal inventory strategy.

(2) With regard to the optimal inventory quantity and optimal inventory cost of the risk-seeking retailer, their monotonicities are positively associated with the retail price, unit shortage cost, and unit residual value, while they are negatively correlated with the wholesale price.

(3) The unit inventory cost has different effects on the optimal inventory quantity and optimal inventory cost. It is negatively correlated with the optimal inventory quantity. Meanwhile, there is a certain 
threshold for unit inventory cost, which makes the monotonicity of the risk-seeking retailer's optimal inventory cost change before and after this threshold. We can explain this counterintuitive phenomenon. Before the unit inventory cost is less than the certain threshold, the increase in the risk-seeking retailer's inventory quantity can still increase the expected profit. At this time, the risk-seeking retailer still increases the inventory quantity, and the inventory cost increases accordingly. When the unit inventory cost exceeds the threshold, the increase in the riskseeking retailer's inventory quantity leads to a decrease in the expected profit. At this time, the riskseeking retailer reduces the inventory quantity, and the corresponding inventory cost also decreases.

(4) From the expressions of the supplier's optimal profit and the profit of the entire supply chain, we can obtain that the supplier's optimal profit and the profit of the entire supply chain are positively associated with the retailer's order quantity. Therefore, the risk-seeking level of the retailer also affects the supplier's profit and supply chain's profit. It is important for the supplier to pay attention to the retailer's risk preference.

(5) We considered only demand as a random variable in our research. There are also price uncertainty and cost uncertainty in practice. It makes sense to study the association of multiple random variables. Some scholars have made attempt methods to describe the relationships between various random variables [52].

Water is regarded as a crucial business resource. This correlational research is carried out from the perspective of supply chain operations and focuses on the optimal inventory strategy of the risk-seeking retailer under RMI mode considering stochastic demand, which makes the research more practical.

\section{Data Availability}

The raw data supporting the conclusions of this article will be made available by the authors, without undue reservation, to any qualified researcher.

\section{Conflicts of Interest}

The authors declare that there are no conflicts of interest regarding the publication of this article.

\section{Acknowledgments}

This work was supported by the National Natural Social Science Foundation of China (Grant no. 20FJYB031).

\section{References}

[1] K. L. Christ and R. L. Burritt, "Supply chain-oriented corporate water accounting: a research agenda," Sustainability Accounting, Management and Policy Journal, vol. 8, no. 2, pp. 216-242, 2017.
[2] P. Rogers, R. Silva, and R. Bhatia, "Water is an economic good: how to use prices to promote equity, efficiency, and sustainability," Water Policy, vol. 4, no. 1, pp. 1-17, 2002.

[3] C. C. Lee and W. H. J. Chu, "Who should control inventory in a supply chain?" European Journal of Operational Research, vol. 164, no. 1, pp. 158-172, 2005.

[4] H. Yu, L. Tang, Y. Xu, and Y. Wang, "How much does VMI better than RMI in a global environment?" International Journal of Production Economics, vol. 170, pp. 268-274, 2015.

[5] A. Hoekstra, Virtual Water Trade: Proceedings of the International Expert Meeting on Virtual Water Trade, UNESCOIHE, Delft, Netherlands, 2003.

[6] I. Hossain, M. Imteaz, and A. Khastagir, "Water footprint: applying the water footprint assessment method to Australian agriculture," Journal of the Science of Food and Agriculture, 2021.

[7] L. Wang, Y. V. Fan, P. S. Varbanov, S. R. W. Alwi, and J. J. Klemeš, "Water footprints and virtual water flows embodied in the power supply chain," Water, vol. 12, no. 11, p. 3006, 2020.

[8] V. Subramaniam, Z. Hashim, S. Loh, and A. Astimar, "Assessing water footprint for the oil palm supply chain- a cradle to gate study," Agricultural Water Management, vol. 237, Article ID 106184, 2020.

[9] C. Naranjo-Merino, O. Ortíz-Rodriguez, and R. Villamizar-G, "Assessing green and blue water footprints in the supply chain of cocoa production: a case study in the northeast of Colombia," Sustainability, vol. 10, no. 1, p. 38, 2018.

[10] R. G. García-Cáceres, M. T. Castañeda-Galvis, and J. F. Suárez-Fajardo, "Towards an efficient and sustainable planning of the drinking water supply chain," Journal of Cleaner Production, vol. 230, pp. 394-401, 2019.

[11] W. Du, Y. Fan, X. Liu, and X. Tang, "Two-part pricing contract and competition between two water supply chains: a theoretical and empirical analysis of the South-to-North Water Transfer Project in China," Journal of Water Supply: Research and Technology-Aqua, vol. 68, no. 3, pp. 197-209, 2019.

[12] Z. Chen and H. Wang, "Water-saving service supply chain cooperation under social welfare maximization," Journal of Water and Climate Change, vol. 11, no. 3, pp. 703-721, 2020.

[13] X. Chen and Z. Chen, "Joint pricing and inventory management of interbasin water transfer supply chain," Complexity, vol. 2020, Article ID 3954084, 16 pages, 2020.

[14] J. Park, S. Park, B. Lim, and C. Kim, "A study of how Supply Chain companies correspond to water risk resulted from climate change," Journal of the Korea Safety Management and Science, vol. 17, no. 1, pp. 149-168, 2015.

[15] C. Sutcliffe, J. Knox, and T. Hess, "Managing irrigation under pressure: how supply chain demands and environmental objectives drive imbalance in agricultural resilience to water shortages," Agricultural Water Management, vol. 243, Article ID 106484, 2021.

[16] M. Mozafari and A. Zabihi, "Robust water supply chain network design under uncertainty in capacity," Water Resources Management, vol. 34, no. 13, pp. 4093-4112, 2020.

[17] Y. Chen, J. Li, H. Lu, and P. Yan, "Coupling system dynamics analysis and risk aversion programming for optimizing the mixed noise-driven shale gas-water supply chains," Journal of Cleaner Production, vol. 278, Article ID 123209, 2021.

[18] J. Shi, H. Li, H. An, J. Guan, and N. Ma, "“What induces the energy-water nexus in China's supply chains?" Environmental Science \& Technology, vol. 54, no. 1, pp. 372-379, 2020. 
[19] X. G. Sánchez-Zarco, E. G. Mora-Jacobo, R. González-Bravo, J. Mahlknecht, and J. M. Ponce-Ortega, "Water, energy, and food security assessment in regions with semiarid climates," Clean Technologies and Environmental Policy, vol. 22, no. 10, pp. 2145-2161, 2020.

[20] M. N. Koleva, A. J. Calderón, D. Zhang, C. A. Styan, and L. G. Papageorgiou, "Integration of environmental aspects in modelling and optimisation of water supply chains," Science of The Total Environment, vol. 636, pp. 314-338, 2018.

[21] J. Li, Q. Su, and L. Ma, "Production and transportation outsourcing decisions in the supply chain under single and multiple carbon policies," Journal of Cleaner Production, vol. 141, pp. 1109-1122, 2017.

[22] K. Anand, R. Anupindi, and Y. Bassok, "Strategic inventories in vertical contracts," Management Science, vol. 54, no. 10, pp. 1792-1804, 2008.

[23] S. Hong and Y. Park, "A comparison study on retailermanaged and vendor-managed inventory policies in the retail supply chain," Journal of the Korean Institute of Industrial Engineers, vol. 32, no. 4, pp. 382-392, 2006.

[24] Y. Li, J. Pan, and X. Tang, "Optimal strategy and cost sharing of free gift cards in a retailer power supply chain," International Transactions in Operational Research, vol. 28, no. 2, pp. 1018-1045, 2021.

[25] M. Braglia, D. Castellano, L. Santillo, and D. Song, "Controlling lead times and minor ordering costs in the joint replenishment problem with stochastic demands under the class of cyclic policies," International Transactions in Operational Research, vol. 28, no. 1, pp. 376-400, 2021.

[26] D. Fiems, E. De Cuypere, K. De Turck, and D. Claeys, "Performance analysis of hybrid MTS/MTO systems with stochastic demand and production," Mathematics, vol. 8, no. 11, p. 1925, 2020.

[27] A. Ghosh, J. K. Jha, and S. P. Sarmah, "Optimal lot-sizing under strict carbon cap policy considering stochastic demand," Applied Mathematical Modelling, vol. 44, pp. 688-704, 2017.

[28] C. K. Chan, F. Fang, and A. Langevin, "Single-vendor multibuyer supply chain coordination with stochastic demand," International Journal of Production Economics, vol. 206, pp. 110-133, 2018.

[29] B. Onggo, J. Panadero, C. Corlu, and A. Juan, "Agri-food supply chains with stochastic demands: a multi-period inventory routing problem with perishable products," Simulation Modelling Practice and Theory, vol. 97, Article ID 101970, 2019.

[30] G. Chavarro, M. Fresen, E. R. González, D. B. Ferro, and H. López-Ospina, "Solving the one-warehouse N-retailers problem with stochastic demand: an inter-ratio policies approach," International Journal of Industrial Engineering Computations, vol. 12, no. 1, pp. 131-142, 2021.

[31] M. Fleischmann, K. Kloos, M. Nouri, and R. Pibernik, "Singleperiod stochastic demand fulfillment in customer hierarchies," European Journal of Operational Research, vol. 286, no. 1, pp. 250-266, 2020.

[32] C. Tang and Y. Wang, "Transportation outsourcing problems considering feasible probabilities under stochastic demands," Computers \& Operations Research, vol. 126, Article ID 105109, 2021.

[33] S. A. Raza, "Price differentiation and inventory decisions in a socially responsible dual-channel supply chain with partial information stochastic demand and cannibalization," Sustainability, vol. 12, no. 22, p. 9577, 2020.
[34] W. Zhang, M. Zhang, W. Zhang, Q. Zhou, and X. Zhang, "What influences the effectiveness of green logistics policies? A grounded theory analysis," Science of the Total Environment, vol. 714, Article ID 136731, 2020.

[35] J. Von Neumann and O. Morgenstern, Theory of Games and Economic Behaviour, Princetown University Press, Cambridge, MA, USA, 1994.

[36] S. H. Zanakis, L. M. Austin, D. C. Nowading, and E. A. Silver, "From teaching to implementing inventory management: problems of translation," Interfaces, vol. 10, no. 6, pp. 103-110, 1980.

[37] C. J. Corbett and L. N. Van Wassenhove, "The natural drift: what happened to operations research?" Operations Research, vol. 41, no. 4, pp. 625-640, 1993.

[38] J. R. Meredith, "Reconsidering the philosophical basis of OR/ MS," Operations Research, vol. 49, no. 3, pp. 325-333, 2001.

[39] V. Tiwari and S. Gavirneni, "ASP, the art and science of practice: recoupling inventory control research and practice: guidelines for achieving synergy," Interfaces, vol. 37, no. 2, pp. 176-186, 2007.

[40] H. Turan, M. Atmis, F. Kosanoglu, S. Elsawah, and M. Ryan, "A risk-averse simulation-based approach for a joint optimization of workforce capacity, spare part stocks and scheduling priorities in maintenance planning," Reliability Engineering \& System Safety, vol. 204, Article ID 107199, 2020.

[41] Y. Song, T. Fan, Y. Tang, and F. Zou, "Quality information acquisition and ordering decisions with risk aversion," International Journal of Production Research, 2021.

[42] B. Li and A. Arreola-Risa, "On minimizing downside risk in make-to-stock, risk-averse firms," Naval Research Logistics (NRL), vol. 68, no. 2, pp. 199-213, 2021.

[43] A. Shapiro and L. Xin, "Technical note-time inconsistency of optimal policies of distributionally robust inventory models," Operations Research, vol. 68, no. 5, pp. 1576-1584, 2020.

[44] W. Du, Y. Fan, and L. Yan, "Pricing strategies for competitive water supply chains under different power structures: an application to the south-to-north water diversion project in China," Sustainability, vol. 10, no. 8, p. 2892, 2018.

[45] M. Li, Q. Fu, P. Vijay, D. Liu, and X. Gong, "Risk-based agricultural water allocation under multiple uncertainties," Agric. Water Manag, vol. 233, Article ID 106105, 2020.

[46] Q. Fu, L. Li, M. Li et al., "An interval parameter conditional value-at-risk two-stage stochastic programming model for sustainable regional water allocation under different representative concentration pathways scenarios," J. Hydrol, vol. 564, Article ID 115e124, 2018.

[47] R. T. Rockafellar and S. Uryasev, "Optimization of conditional value-at-risk," The Journal of Risk, vol. 2, no. 3, pp. 21-41, 2000.

[48] S. Poormoaied and Z. Atan, "A multi-attribute utility theory approach to ordering policy for perishable items," International Journal of Production Economics, vol. 225, Article ID 107582, 2020.

[49] X. Xu, Z. Meng, P. Ji, C. Dang, and H. Wang, "On the newsvendor model with conditional Value-at-Risk of opportunity loss," International Journal of Production Research, vol. 54, no. 8, pp. 2449-2458, 2016.

[50] P. Kouvelis and R. Li, "Integrated risk management for newsvendors with value-at-risk constraints," Manufacturing \& Service Operations Management, vol. 21, no. 4, pp. 816-832, 2019.

[51] H. Jian and M. Xu, "Models and their experiments of supply chain contracts based on CVaR," Journal of Management Sciences in China, vol. 18, no. 10, pp. 56-68, 2015. 
[52] S. Zhou, C. Wang, and L. Shao, "Decision on single-period optimal order quantity by using copula-CVaR based on stochastic cost and price," Operations Research and Management Science, vol. 29, no. 4, pp. 138-146, 2020. 